\title{
Response compatibility in transfer from aversive to appetitive training
}

\author{
MARVIN G. BULGATZ \\ Eastern Montana College, Billings, Montana 59101 \\ and \\ HAROLD BABB \\ State University of New York, Binghamton, New York 13901
}

\begin{abstract}
In transfer from shock escape to appetitively motivated training in a straight runway, 64 male hooded rats were given various pretreatments, or none, prior to transfer. With appropriate controls, running was motivated by high-intensity noise $(120 \mathrm{~dB})$ or shock $(1 \mathrm{~mA})$, by low-intensity shock (.2 $\mathrm{mA})$, or by a second-order aversive excitatory stimulus prior to the elimination of those stimulus conditions and the initiation of food reinforcement. In general, all of the pretreatments produced extended suppression in the transfer condition. Controls for latent inhibition indicated none was present. High-intensity shock reduced eating on initial food reinforcement trials, but the other aversive conditions did not. The results were interpreted as possible consequences of stimulus-directive effects.
\end{abstract}

There is now a substantial amount of reasonably consistent evidence that transfer from aversive to appetitive training in the runway produces suppressed responding in the transfer situation in comparison with a procedure in which the prior aversive training is not given (Babb, 1963; Babb \& Leask, 1969; Mellgren, Haddad, Dyck, \& Eckert, 1976; Nation, Wrather, Mellgren, \& Spivey, 1980; Stoffer \& Babb, 1976). One important theoretical question is whether such effects are attributable to some form of response competition or to some more central incompatibility between appetitive and aversive stimulation (Dickinson \& Pearce, 1977). While the molar response of running to the goalbox is the same for aversive and appetitive conditions, the molecular components could be different, and possibly competitive (Babb, Bulgatz, \& Matthews, 1969).

One way to test for the effects of response competition would be to use an aversive stimulus other than shock, such as loud noise, on the presumption that noise would elicit kinds of component responding that could be different from those elicited by the application of shock to the feet of the animals. Another way of testing for response compatibility would be to use secondorder conditioning, on the presumption that any such conditioning produced by an "off-baseline" conditioning procedure and tested in the runway should be reasonably divorced from first-order response-eliciting effects. If suppressive effects were obtained from the second-order conditioning procedure, it would emphasize the generality of whatever process underlies the production of suppression, and it would also emphasize

This report is based on a dissertation submitted to the University of Montana by Marvin G. Bulgatz in partial fulfillment of requirements for the PhD degree. the ability of second-order conditioning to produce effects that are transferable to instrumental responding in the runway. Accordingly, a noise CS was paired with shock, presented randomly with shock, or given without shock in a behavior-restricting apparatus, and then subjects were transferred to noise alone in the runway. To control for possible latent inhibition effects (Lubow, 1973), other animals were presented high-intensity noise, high-intensity shock, or low-intensity shock in the conditioning apparatus and then given those same stimuli in the runway. A separate group was not given prior exposure to high shock but was run on high shock in the runway along with the prior exposure groups. Finally, all groups, with one new group, were given training in the runway with food reinforcement and without any of the formal stimulus conditions that differentiated groups in the earlier training. Both starttime and run-time measures were recorded, but, in addition, a record was also kept of the number of food pellets consumed on each food-reinforced trial. The latter measure was taken as a test for possible generalization of aversive effects from the startbox and alley to the goalbox.

\section{METHOD}

Subjects

The subjects were 64 male Long-Evans hooded rats that were approximately 90 days of age on Day 1 of pretraining.

\section{Apparatus}

The basic apparatus consisted of a straight runway that was $122 \mathrm{~cm}$ long with $30.5 \mathrm{~cm}$ startbox and goalbox extensions. It was $12.7 \mathrm{~cm}$ high and $12.7 \mathrm{~cm}$ wide, except that the goalbox was $25.4 \mathrm{~cm}$ wide. It was covered with clear acrylic and it contained clear acrylic guillotine startbox and goalbox doors that were channeled in aluminum frames abutting $2 \mathrm{~cm}$ into the alley on both sides. The floor was composed of $.64-\mathrm{cm}$ stainless steel 
bars spaced $.64 \mathrm{~cm}$ apart. The inside rear wall of the startbox contained a $7.6-\mathrm{cm}$ speaker that was centered on the wall, mounted flush, and covered with a wire screen. In addition, the goalbox contained a $5-\mathrm{cm}$ "sight barrier" that was placed $15.2 \mathrm{~cm}$ in front of, and parallel to, the rear wall. Except for the doors and door frames and the top and grid floor, all parts of the runway were painted a medium gray. Associated equipment consisted of Hunter silent photorelays and timers, an Applegate shock source, a Davis shock scrambler, a Grayson-Stadler $455 \mathrm{C}$ noise generator, and a Dynakit Mark IV amplifier.

In addition to the runway apparatus, a chamber was constructed for prerunway training. It consisted of $.32-\mathrm{cm}$ brass rods molded into circles and mounted flush to the inside surface of $8.2-\mathrm{cm}$ plastic railings. The chamber was $17.2 \mathrm{~cm}$ long, had a $7-\mathrm{cm}$ diameter, and contained a circular door in one end through which subjects could be inserted or removed. The chamber was housed in a black sound-treated enclosure that was $30.5 \mathrm{~cm}$ high and wide and $38 \mathrm{~cm}$ long. A $7.6-\mathrm{cm}$ speaker was centered and mounted flush on the inside rear wall.

Stimuli used consisted of $90-\mathrm{dB}$ and $120-\mathrm{dB}$ white noise and 1.0-mA and .2-mA shock. The ambient noise level was approximately $60 \mathrm{~dB}$ inside the experimental room and inside the conditioning chamber. For convenience, the $90-\mathrm{dB}$ level will be referred to as low noise (LN), the $120-\mathrm{dB}$ level as high noise (HN), the .2-mA shock as low shock (LS), and the $1.0-\mathrm{mA}$ shock as high shock (HS).

\section{Procedure}

All subjects were placed on $22-\mathrm{h}$ food deprivation at the start of pretraining and were kept on that schedule throughout the experiment. They were initially given $3 \mathrm{~min}$ of handling each day for 4 days. On the next 12 days, they were individually allowed $3 \mathrm{~min}$ of access to a tray of $45 \mathrm{-mg}$ Noyes food pellets placed on a metal table that was located outside the experimental room.

After pretraining, the 64 subjects were divided into eight groups of 8 subjects each, and six of the eight groups were given 8 trials/day for 4 days in the brass-rod chamber. For the LN-HS group, each trial consisted of a paired presentation of low noise and high shock. The noise preceded the shock by $3 \mathrm{sec}$ and terminated with it $.5 \mathrm{sec}$ later. The intertrial interval and range were 30 and $10 \mathrm{sec}$, respectively. A second group, LN/HS, received unpaired presentations of low noise and high shock, and a third group, LN, received low noise alone. A fourth group, HS, received high shock alone, and a fifth group, $\mathrm{HN}$, received .5 -sec presentations of the $120-\mathrm{dB}$ noise. Similarly, the sixth group, LS, experienced $.5 \mathrm{sec}$ presentations of the $.2-\mathrm{mA}$ shock.

After training in the chamber, the six groups were given 15 trials in the runway, 5 trials on each of 3 days. The LN-HS and LN/HS groups received the LN stimulus alone, without shock, and the other groups, including the LN group, received the same stimulus condition (HN, HS, or LS) they had experienced in the prerunway chamber. For all of the groups, the appropriate stimulus came on simultaneously with the opening of the startbox door and terminated as the subject entered the goalbox, where it was allowed to remain for $30 \mathrm{sec}$. It was then removed to a small gray retaining compartment where it remained for the duration of the intertrial interval, which was approximately $10 \mathrm{~min}$. At the end of each day's runway session, subjects were given two trials in the brass-rod chamber under the identical conditions of initial training. It was assumed that those trials would help to maintain effects of the original chamber training. Additionally, one new group was started on runway training when the six chamber-trained groups were transferred to it. This new group, $H S$, which had not received any chamber training, was otherwise treated identically to the HS group.

After the 15 trials of runway training, all seven groups, plus one new one, $\mathrm{C}$, which had received neither chamber training nor runway training, were given 5 trials/day in the runway, for 10 days, with a tray of 25 Noyes $.45-\mathrm{mg}$ pellets in the goalbox on each trial. At the end of each run, the animal was allowed to remain in the goalbox for $30 \mathrm{sec}$ and was then moved to the gray retaining compartment for an intertrial interval of approximately $10 \mathrm{~min}$. The number of pellets eaten on each trial was recorded, along with start and run times. It should be especially noted that neither noise nor shock stimuli were present during this food reinforcement phase of training.

\section{RESULTS}

Scores for each of the five runway trials were transformed into speed measures by taking the reciprocal of the median and multiplying by 100 . Analyses were performed separately on start and run speeds. On the first 15 trials of runway training (LN, HN, HS, and LS conditions only), main effects for start speeds $[F(7,56)$ $=22.1, \mathrm{p}<.001]$ and run speeds $[\mathrm{F}(7,56)=47.1$, $\mathrm{p}<.001$ ] were both significant (see Figure 1). In determining simple effects, no differences were obtained between Groups HS and $H S$ on either measure, and they were combined in comparisons with other groups. In that regard, Group HN was faster than LN-HS [t $(56)=$ $2.11, \mathrm{p}<.05]$, and since the latter group ranked second in starting speed, $\mathrm{HN}$ was faster than the other groups. Group LN-HS was faster than HS [ $\mathrm{t}(56)=3.3, \mathrm{p}<.01]$ and therefore faster than LS and LN, since the latter
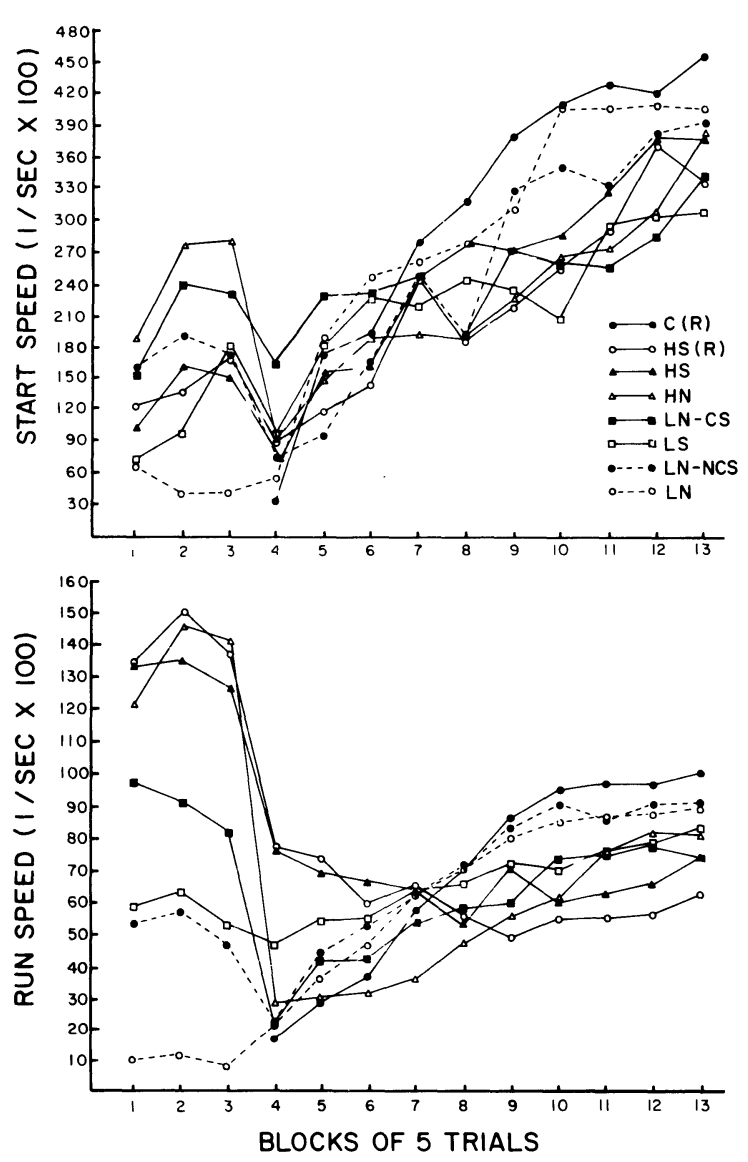

Figure 1. Start and run speeds in aversive training (Trials 1-15) and in food reinforcement training (Trials 16-65). 
two groups ranked lower than HS. In addition, Group LS started faster than Group LN [t(56) $=3.1, \mathrm{p}<.01]$.

In regard to simple effects with run speeds on the first 15 runway trials, Groups HN and HS were highly similar, and the lower ranked one, Group HS, was significantly faster than Group LN-HS $[\mathrm{t}(56)=4.1$, $\mathrm{p}<.001]$, which was faster than Group LS [t(56) $=3.1$, $\mathrm{p}<.01]$. More important, Group LN-HS was faster than Group LN/HS $[\mathrm{t}(56)=3.6, \mathrm{p}<.001]$, which, in turn, was faster than Group LN $[\mathrm{t}(56)=4.0, \mathrm{p}<.001]$.

For the food reinforcement phase, analyses were done on start speeds for Trials 31-65 and on run speeds for Trials 36-65. These were the last 30-35 trials of foodmotivated training. Main effects were significant for both start speeds $[F(7,56)=5.52, \mathrm{p}<.001]$ and run speeds $[F(7,56)=3.18, p<.01]$. In regard to simple effects for start speeds, Group $C$, the group that received only food reinforcement training, started faster than Groups LN-HS $[\mathrm{t}(56)=3.79, \mathrm{p}<.001]$, HS [t(56) $=$ $2.89, \mathrm{p}<.01], \mathrm{LS}[\mathrm{t}(56)=4.19, \mathrm{p}<.001], \mathrm{HN}[\mathrm{t}(56)$ $=4.28, \mathrm{p}<.001]$, and $H S[\mathrm{t}(56)=4.60, \mathrm{p}<.001]$, but Group $C$ was not significantly different from Groups LN and LN/HS. Similarly, for run speeds, Group C again was faster than Groups HS [ $\mathrm{t}(56)=2.22$, $\mathrm{p}<.05], H S[\mathrm{t}(56)=2.50, \mathrm{p}<.05], \mathrm{HN}[\mathrm{t}(56)=2.66$, $\mathrm{p}<.05]$, and LN-HS [t(56)=3.81, $\mathrm{p}<.001]$, but Group C did not differ from Groups LN/HS, LN, and LS.

Analyses were also done on the number of food pellets consumed on Runway Trials 16-35 $[\mathrm{F}(7,56)=$ $5.58, \mathrm{p}<.001]$, the first 20 trials of the food reinforcement phase, and on Trials $36-65[F(7,56)]<1$, $p>.05]$, which were the same trials on which run speeds were analyzed. With regard to simple effects on Trials 16-35, Group HS ate fewer pellets than Groups C $[\mathrm{t}(56)=4.40, \mathrm{p}<.001], \mathrm{LN}-\mathrm{HS}[\mathrm{t}(56)=4.50, \mathrm{p}<.001]$, and $\mathrm{HN}[\mathrm{t}(56)=2.6, \mathrm{p}<.05]$, and Group $H S$ ate fewer pellets than Groups $\mathrm{C}[\mathrm{t}(56)=3.7, \mathrm{p}<.001]$ and LN-HS $[t(56)=3.8, p<.001]$. No other differences were significant.

\section{DISCUSSION}

On the initial preappetitive runway trials, with escape training conditions in force, no differences were present between the HS group that had received high shock in the conditioning apparatus and the $H S$ group that had not, suggesting that there were no important preexposure effects. The second-order conditioning group, LN-HS, started faster than the LN group and ran faster than the LN/HS and LN groups, demonstrating that the CS-US pairing procedure had been effective. Moreover, both the high-intensity noise and the high-intensity shock groups ran faster than their respective low-intensity controls.

In the food reinforcement phase, all of the groups except LN and LN/HS, as well as LS in the case of run speeds, were suppressed in responding in comparison with the control group. In that context, the fact that high noise produced suppression indicates that the suppression effects are not a specific product of shock stimulation. Moreover, that finding also argues against the idea that competition between response components is responsible for those effects, since the response components produced by shock would presumably be different from those produced by noise. Similarly, when the buzzer CS had previously been paired with shock, 15 trials of buzzer-motivated running made the startbox and alley and the operation of the startbox door sufficiently aversive to produce suppression in later foodmotivated running, which constitutes further evidence that response incompatibility is unlikely to be responsible for the suppression effects.

Considering the possibility that aversive stimulation reduces hunger motivation (Estes, 1969), only the high-shock groups ate less than the control group on the first 20 trials of the food reinforcement phase, and there were no significant differences between groups on the last 30 trials. Since amount of reinforcement is generally presumed to be a performance variable, rather than an associative one, any differential influence of the amount eaten on the first 20 trials is not likely to be responsible for significant differences in start speeds and run speeds on the last 30 . In addition, neither the high-noise group nor the secondorder conditioning group were significantly different from the control group in amount eaten, but both groups were inferior to the control group in runway performance. Nevertheless, the results do indicate that the effects of shock stimulation generalized to the goalbox and reduced the consumption of food on initial food-motivated trials.

Since the differences between groups do not seem to be readily accounted for on a basis of response incompatibility or inferior hunger motivation, some "affective incompatibility" (Hall \& Pearce, 1978) produced by aversive and appetitive stimulation could be deemed responsible. Dickinson and Pearce (1977) have argued that a central process is involved, making excitors and inhibitors of contrasted affective value equivalent. However, the only "central" process that has been identified as a possible candidate is Sherrington's (1947) neural concept of "reciprocal inhibition" (e.g., Estes, 1969; Miller, 1963; Stein, 1964; Wolpe, 1958), and the adequacy of that concept as an explanation of a "central process" is questionable.

Perhaps a different perspective on the concept of response compatibility could provide an answer to the problem. Research relating to autoshaping (Brown \& Jenkins, 1968) and signtracking (Hearst \& Jenkins, 1977) provides evidence for stimulusdirected movements and movement tendencies in appetitively motivated situations, and similar findings are being obtained in regard to aversive stimulation (e.g., Bartter \& Masterson, 1980; Karpicke, Christoph, Peterson, \& Hearst, 1977; Karpicke \& Dout, 1980; Leclerc \& Reberg, 1980). In terms of the present experiment, aversive unconditioned stimuli, such as intense noise and shock, are presumed to energize behavior and to direct it away from their respective spatial locations. They also make conditioned aversive excitatory stimuli of the stimulus complex that is concurrently present with shock, including any formal conditioned stimuli, and those stimuli also energize behavior and direct it away from their respective locations (Babb, 1980; Babb, Kostyla, \& Bennett, 1980). If the animals subsequently receive food in the goalbox, the startbox and alley stimuli that precede food should become conditioned appetitive excitatory stimuli and become attracting, but their initial repellant characteristics might retard that process in comparison with nonshocked controls.

\section{REFERENCES}

BABB, H. Transfer between habits based on shock and thirst. Journal of Comparative and Physiological Psychology, 1963, 56, 318-323.

BABB, H. Facilitation by goal punishment after escape conditioning: CS intensity effects. Psychological Record, 1980, 30, 229-236.

Babb, H., Bulgatz, M. G., \& Matrhew8, L. J. Transfer from shock-escape to thirst- or hunger-motivated responding. Journal of Comparative and Physiological Psychology, 1969, 67, 129-133.

BABB, H., Kostyla, S. J., \& BennetT, W. R. Escape conditioning and goal punishment: Effects of acquisition trials, initial punishment trials, and CS extent. Learning and Motivation, $1980,11,386-406$.

BАBв, H., \& LEAsK, J. K. Response suppression after transfer 
from shock-escape to thirst-motivated training. Psychonomic Science, 1969, 14, 23-24.

BartTer, W. D., \& MAsterson, F. A. Is there sign-tracking in aversive conditioning? Bulletin of the Psychonomic Society, $1980,15,87-89$.

Brown, P. L., \& Jenkins, H. M. Auto-shaping of the pigeon's keypeck. Journal of the Experimental Analysis of Behavior, 1968, 11, 1-8.

Dickinson, A., \& Pearce, J. M. Inhibitory interactions between appetitive and aversive stimuli. Psychological Bulletin, 1977, 84, 690-711.

Estes, W. K. Outline of a theory of punishment. In R. M. Church \& B. A. Campbell (Eds.), Punishment and aversive behavior. New York: Appleton-Century-Crofts, 1969.

Guthrie, E. R. The psychology of learning (Rev. ed.). New York: Harpur, 1952.

Hall, G., \& Pearce, J. M. Transfer of learning across reinforcers: Appetitive discrimination learning between stimuli previously associated with shock. Quarterly Journal of Experimental Psychology, 1978, 30, 539-549.

Hearst, E., \& Jenkins, H. M. Sign-tracking: The stimulusreinforcer relation and directed action. Austin, Tex: Psychonomic Society, 1974.

Karpicke, J., Christoph, G., Peterson, G., \& Hearst, E. Signal location and positive versus negative conditioned suppression in the rat. Journal of Experimental Psychology: Animal Behavior Processes, 1977, 3, 105-118.

KARPICKE, J., \& DoUT, D. Withdrawal from signals for imminent inescapable electric shock. Psychological Record, 1980, 30, 511-523.
LeCLerc, R., \& Rebera, D. Sign-tracking in aversive conditioning. Learning and Motivation, 1980, 11, 302-317.

Lubow, R. E. Latent inhibition. Psychological Bulletin, 1973, 79, 398-407.

Mellaren, R. L., Haddad, N., Dyck, D. G., \& Eckert, E. Transfer of escape conditioning to extinction of a foodreinforced response. Animal Learning \& Behavior, 1976, 4, 247-256.

Miller, N. E. Some reflections on the law of effect produce a new alternative to drive reduction. In $M$. R. Jones (Ed.), Nebraska Symposium on Motivation (Vol. 11). Lincoln: University of Nebraska Press, 1963.

Nation, J. R., Wrather, D. M., Mellaren, R. L., \& Spivey, M. Transfer of the partial reinforcement extinction effect between escape (shock) and appetitive (food) conditioning. Learning and Motivation, 1980, 11, 97-116.

Sherrinaton, C. S. The integrative action of the central nervous system. Cambridge: Cambridge University Press, 1947.

STE IN, L. Reciprocal action of reward and punishment mechanisms. In R. G. Heath (Ed.), The role of pleasure in behavior. New York: Harper \& Row, 1964.

Stoffer, G. R., \& BABB, H. Transfer suppression of a hungermotivated response as a function of the number of prior escape or avoidance trials. Bulletin of the Psychonomic Society, 1976, 7, 471-474.

Wolpe, J. Psychotherapy by reciprocal inhibition. Stanford, Calif: Stanford University Press, 1958.

(Received for publication October 16, 1981.) 